\title{
Transition to Lead-Free Products in the US Electronics Industry: A Model of Environmental, Technical, and Economic Preferences
}

\author{
Xiaoying Zhou • Hilary Nixon - Oladele A. Ogunseitan • \\ Andrew A. Shapiro • Julie M. Schoenung
}

Received: 11 June 2008 /Accepted: 16 May 2010 /Published online: 4 June 2010

(C) The Author(s) 2010. This article is published with open access at Springerlink.com

\begin{abstract}
The European Union's Restriction on the Use of Certain Hazardous Substances (Directive 2002/95/EC) targeted at electronic products took effect in 2006. In contrast, the USA has no comparable national policy on these products. To understand corporate responses to policy differences across jurisdictions, we conducted a structuredquestionnaire survey of individuals in 109 companies that are representative of the US electronics industry. The results reveal that $70 \%$ of these companies have already adopted lead-free solder for electronics with $49 \%$ of the total preferring the $\mathrm{SnAgCu}$ formulation, despite uncertainties associated with environmental impacts of this alternative
\end{abstract}

Note: The order of authors $2-4$ follows alphabetical order.

X. Zhou $\cdot$ J. M. Schoenung $(\bowtie)$

Department of Chemical Engineering and Materials Science,

University of California,

Davis, CA, USA

e-mail: jmschoenung@ucdavis.edu

X. Zhou

e-mail: xzhou@dtsc.ca.gov

H. Nixon

Department of Urban and Regional Planning,

San Jose State University,

San Jose, CA, USA

e-mail: hilary.nixon@sjsu.edu

O. A. Ogunseitan

Program in Public Health and School of Social Ecology,

University of California,

Irvine, CA, USA

e-mail: Oladele.Ogunseitan@uci.edu

\section{A. A. Shapiro}

Department of Electrical Engineering and Computer Science,

University of California,

Irvine, CA, USA

e-mail: aashpir@uci.edu alloy. We use a modified life cycle impact assessment method based on endpoint modeling approach to derive weighting factors that represent the respondents' value system for tradeoffs among environmental impacts. We use a modified fuzzy Technique for Order Preference by Similarity to Ideal Solution approach to evaluate technical criteria dominance in declared preferences. A statistical model of corporate behavior is also presented. The results provide the first systematic framework that accounts for environmental impact, technological challenge, and business strategy concurrently toward formulating a comprehensive national policy for materials selection in electronic products.

Keywords Decision making · Environmental management $\cdot$ E-waste $\cdot$ Integrated assessment $\cdot$ Lead-free solder. Materials selection

\section{Introduction}

Electronic waste (e-waste) contains a wide variety of heavy metals including lead. Evidence from Europe suggests that it is the fastest-growing lead-containing hazardous waste category [1], and concern about the potential environmental impact has resulted in targeted lead phase-out initiatives and innovation in the electronics assembly industry. In response to the threats posed by lead to environmental quality and human health, the European Union implemented Directives 2002/95/EC (Restriction of Certain Hazardous Substances in Electrical and Electronic Equipment; RoHS) and 2002/96/ EC (Waste Electrical and Electronic Equipment; WEEE) effective July 1, 2006. The RoHS Directive restricts the use of six hazardous materials including lead in the manufacture of various types of electronic and electrical equipment [2], whereas the WEEE Directive sets collection, recycling, and 
recovery targets for electrical products [3], Japan, China, and South Korea are also promoting similar legislation to limit the lead content of e-waste.

Currently, the USA does not have national legislation restricting lead-containing solders in electronics, although some states have made progress on legislation to restrict substances in electronic products $[4,5]$. However, in the absence of a national agenda to reduce toxic materials in electronics, gaps persist in regional policies that may confuse manufacturers and consumers, prolonging potential human and environmental exposure to detrimental effects of hazardous e-waste [6].

As the debate on the adoption of lead-free components and regulatory policies continues, uncertainties about alternative materials, product performance, consumer preferences, and costs have also emerged [7-9].

Although a number of investigators have independently explored technological design or environmental impact of lead-free alternatives, very little research has been conducted to integrate assessments of environmental impact, technological challenges, and business strategies, during the transition of phasing out lead in electronics. Our research focuses on corporate perceptions regarding lead-free electronics while taking these tradeoffs into account. Our primary goal is to contribute information toward the development of an explanatory model of corporate responsibility in handling risk and uncertainty about legislation associated with potentially hazardous products. Moreover, we derive a quantitative case-specific weighting scheme for corporate stakeholders and we compare this scheme with other established generic weighting schemes derived for the general public through life cycle impact assessment.

\section{Survey Design}

We targeted corporations that have direct experience with the adoption of lead-free solders or that will be affected by emerging international lead-free legislation. Between October and December 2005, we conducted a web-based structured survey, targeted at 1,134 individuals from the Association Connecting Electronics Industries (IPC) membership directory regarding preferences and priorities with respect to adoption of lead-free solder in electronic and electrical products. IPC membership represents the US-based electronics interconnection industry, including design, printed wiring board manufacturing, and electronics assembly. The distribution of survey respondents' corporate characteristics is comparable with IPC membership (Table 1). Web-based surveys were completed by respondents who agreed to participate in the survey in response to an email invitation and two follow-up email reminders.

The survey questionnaire consisted of four parts: Part I focused on respondents' knowledge of general policies dealing with environmental management; Part II inquired about corporate involvement, strategies for lead-free solder adoption, and challenges associated with the lead-free transition; Part III elicited respondents' preferences regarding environmental tradeoffs through scenarios designed for
Table 1 Comparison of company type for 109 survey respondents and IPC membership

\footnotetext{
${ }^{a}$ The company of a survey respondent can possess different business types simultaneously
}

\begin{tabular}{|c|c|c|c|}
\hline Sectors & $\begin{array}{l}\text { Survey } \\
\text { respondent } \\
\text { breakdown }^{\mathrm{a}}\end{array}$ & $\begin{array}{l}\text { IPC } \\
\text { membership } \\
\text { breakdown }\end{array}$ & $\begin{array}{l}\text { Survey respondent } \\
\text { breakdown by subsectors }{ }^{\mathrm{a}}\end{array}$ \\
\hline Original electronic manufacturers & $41 \%$ & $34 \%$ & - \\
\hline \multirow{4}{*}{$\begin{array}{l}\text { Electronic manufacture } \\
\text { service companies }\end{array}$} & \multirow[t]{4}{*}{$28 \%$} & \multirow[t]{4}{*}{$20 \%$} & Final product assembly (22\%) \\
\hline & & & $\begin{array}{l}\text { Printed wiring board assembly } \\
(24 \%)\end{array}$ \\
\hline & & & Design $(16 \%)$ \\
\hline & & & Others $(5 \%)$ \\
\hline $\begin{array}{l}\text { Printed wiring board } \\
\text { manufacturer }\end{array}$ & $4 \%$ & $10 \%$ & - \\
\hline \multirow[t]{4}{*}{ Suppliers } & \multirow[t]{4}{*}{$20 \%$} & \multirow[t]{4}{*}{$26 \%$} & Component supplier (6\%) \\
\hline & & & Equipment supplier (7\%) \\
\hline & & & Solder supplier $(6 \%)$ \\
\hline & & & Raw material supplier (4\%) \\
\hline $\begin{array}{l}\text { Original design } \\
\text { manufacturers }\end{array}$ & $28 \%$ & - & - \\
\hline \multirow[t]{5}{*}{ Others } & \multirow[t]{5}{*}{$14 \%$} & \multirow[t]{5}{*}{$10 \%$} & Recycler (4\%) \\
\hline & & & Retailer (1\%) \\
\hline & & & Consultancy (5\%) \\
\hline & & & Academia (7\%) \\
\hline & & & Trade association $(1 \%)$ \\
\hline
\end{tabular}


a conjoint rating analysis; and Part IV collected information about the respondents' sociodemographic characteristics and the corporate profile.

A detailed guideline for the survey structure and how the results were analyzed is presented in Fig. 1. We relied on a modified conjoint analysis model [life cycle impact assessment method based on endpoint modeling (LIME)], a modified fuzzy analysis model [Technique for Order Preference by Similarity to Ideal Solution (TOPSIS)], and a binary logit regression model to interpret the responses from three perspectives - environmental impacts, technological challenges, and business strategy.

\section{Survey Results and Analysis}

\subsection{General Profile}

A total of 109 responses were received, representing a response rate of $9.6 \%$, which is comparable with various electronics industry surveys $[10,11]$. The respondents are from a cross section of companies that supply the solder products, components, or equipment, electronic manufacture service (EMS) companies that apply the solders in the assembly process, original equipment manufacturer (OEM) companies that sell lead-free products, recycling companies, academic and research institutions or consulting firms that provide lead-free implementation and research services, and some public interest groups in the USA. Most of the companies engage in domestic manufacturing activities and international marketing. Company scale (based on number of employees) varies widely. The company profile breakdown is shown in Table 2. The positions held by respondents at the time of the survey are presented in Fig. 2.

Seventy percent of the respondents' companies had already adopted lead-free solder for electronic or electrical products, in response to international lead-free initiatives. Table 2 also shows the technical focus and phases of the corporate adoption of lead-free solder at the time the survey was conducted. The rank order of alternative lead-free alloys adopted by US electronics industries is as follows: $\mathrm{SnAgCu}$ (49\%), $\mathrm{SnCu}(10 \%), \mathrm{SnAg}(9 \%), \mathrm{SnBiAgCu}(4 \%), \mathrm{SnIn}-$ BiAg (2\%), SnSb (2\%), SnZnBi (2\%), SnZn (2\%), and others (20\%). This distribution of lead-free materials

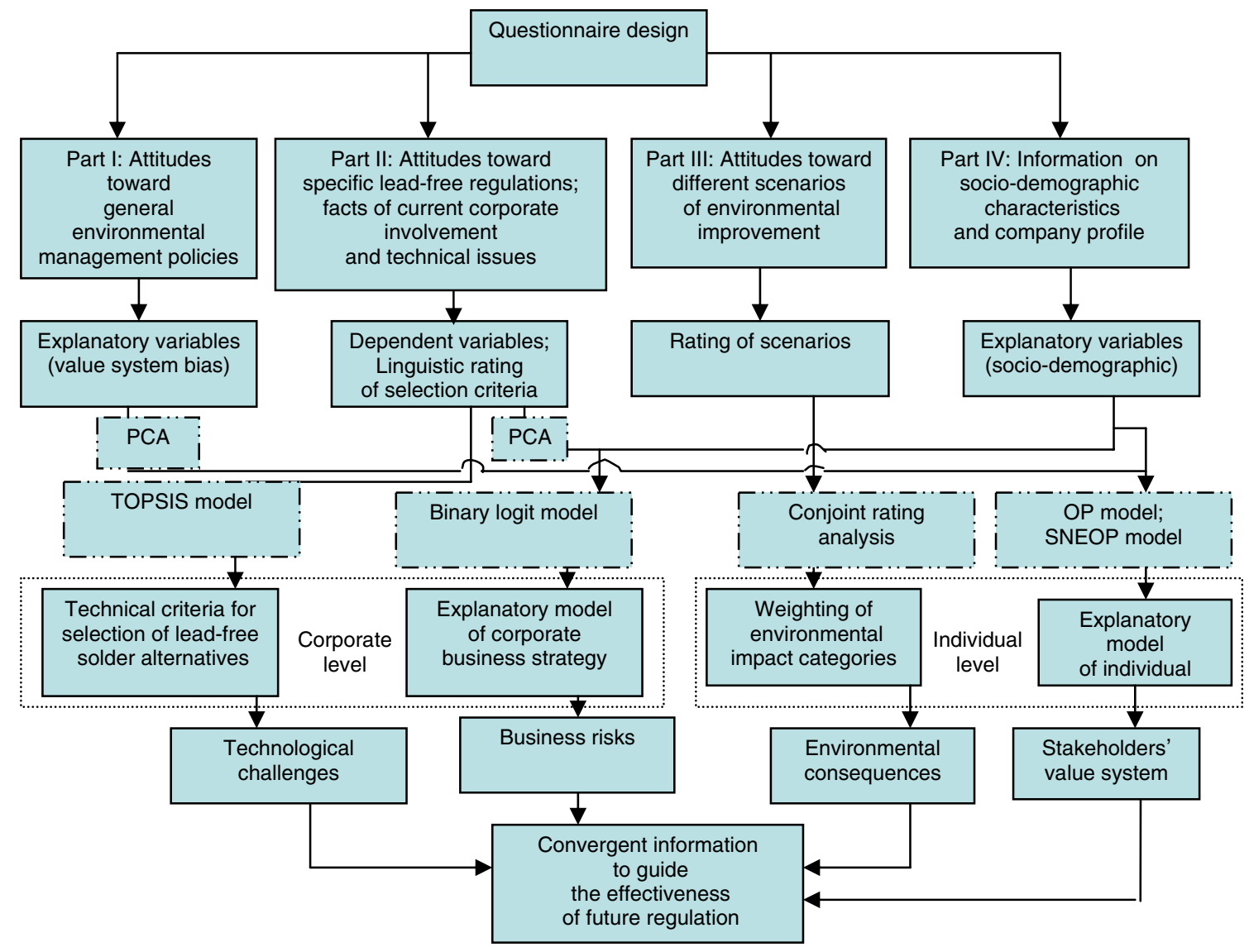

Fig. 1 Roadmap of the structured survey questionnaire design and methodology. PCA principal component analysis, TOPSIS Technique for Order Preference by Similarity to Ideal Solution, $O P$ ordinary probit model, SNEOP semi-nonparametric estimation of extended ordered probit model, dashed-dotted box analytical methodologies 
Table 2 Company profile breakdown percentage for 109 survey responses

\begin{tabular}{|c|c|c|c|c|}
\hline \multirow[t]{7}{*}{ Adoption of $\mathrm{Pb}$-free system } & \multirow[t]{6}{*}{ Yes } & \multirow[t]{2}{*}{ Solder technology } & $\begin{array}{l}\text { Wave soldering }(12 \%) \\
\text { Reflow soldering }(17 \%)\end{array}$ & \multirow[t]{6}{*}{$70 \%$} \\
\hline & & & Both technologies $(47 \%)$ & \\
\hline & & \multirow[t]{4}{*}{ Status of adoption } & Data collection $(12 \%)$ & \\
\hline & & & Tests and trials $(18 \%)$ & \\
\hline & & & Pilot processing $(18 \%)$ & \\
\hline & & & Salable products $(25 \%)$ & \\
\hline & No & & & $30 \%$ \\
\hline \multirow[t]{3}{*}{ Company scope } & \multicolumn{3}{|c|}{ Headquarters in USA } & $91 \%$ \\
\hline & \multicolumn{3}{|c|}{ Manufacturing line in USA } & $67 \%$ \\
\hline & \multicolumn{3}{|c|}{ International market } & $75 \%$ \\
\hline \multirow[t]{6}{*}{ Company scale } & \multicolumn{3}{|c|}{ Less than 20 employees } & $9 \%$ \\
\hline & \multicolumn{3}{|c|}{ 20-50 employees } & $12 \%$ \\
\hline & \multicolumn{3}{|c|}{ 50-100 employees } & $8 \%$ \\
\hline & \multicolumn{3}{|c|}{ 100-500 employees } & $26 \%$ \\
\hline & \multicolumn{3}{|c|}{ 500-1,000 employees } & $12 \%$ \\
\hline & \multicolumn{3}{|c|}{ More than 1,000 employees } & $28 \%$ \\
\hline \multirow[t]{14}{*}{ Trade association } & \multicolumn{3}{|c|}{ Association Connecting Electronic Industries } & $86 \%$ \\
\hline & \multicolumn{3}{|c|}{ American Electronics Association } & $13 \%$ \\
\hline & \multicolumn{3}{|c|}{ Electronic Industrial Alliance } & $10 \%$ \\
\hline & \multicolumn{3}{|c|}{ Telecommunications Industry Association } & $6 \%$ \\
\hline & \multicolumn{3}{|c|}{ Government Electronics and Information Technology Association } & $3 \%$ \\
\hline & \multicolumn{3}{|c|}{ JEDEC Solid State Technology Association } & $16 \%$ \\
\hline & \multicolumn{3}{|c|}{ International Tin Research Institute } & $6 \%$ \\
\hline & \multicolumn{3}{|c|}{ Electronic Product Recovery and Recycling Roundtable } & $2 \%$ \\
\hline & \multicolumn{3}{|c|}{ Industry Council for Electronic Equipment Recycling } & $3 \%$ \\
\hline & \multicolumn{3}{|c|}{ Institute of Electrical and Electronics Engineers } & $44 \%$ \\
\hline & \multicolumn{3}{|c|}{ International Association of Electronic Recyclers } & $1 \%$ \\
\hline & \multicolumn{3}{|c|}{ Microelectronics and Computer Technology Corporation } & $3 \%$ \\
\hline & \multicolumn{3}{|c|}{ Multi-Lifecycle Engineering Research Center } & $1 \%$ \\
\hline & \multicolumn{3}{|c|}{ Others, mostly identified as the Surface Mount Technology Association } & $21 \%$ \\
\hline
\end{tabular}

selection meets our expectations because the tin-silvercopper family of solders has been recommended by most industry organizations, such as the National Electronics Manufacturing Initiative, the Japanese Electronic Industry Development Association, and the European community [5].

\subsection{Elicitation of Lead-Free Solder Environmental Tradeoff Preference Structure by a Conjoint Rating Analysis}

Although only $1.5-2.5 \%$ of total lead consumption is in the electronics industry, consumer e-waste represents $40 \%$ of the lead found in landfills [12]. Various leaching tests demonstrate that lead leaches to levels greater than the Resource Conservation and Recovery Act toxicity characteristic limit (5 mg/l) in either solder scrap or printed wiring board scrap [13-16], which explains toxicity concerns about lead leaching out of e-waste in landfills. Despite the precautionary principle, as incorporated in the RoHS Directive, the comments received from this survey reflect the doubts about the tangible benefits of lead-free solders. These uncertainties have also been reported by several research publications. For example, some elements replacing lead used for solders in electronic products, including $\mathrm{Ag}$, $\mathrm{Cu}, \mathrm{Bi}$, and $\mathrm{Zn}$ have serious environmental impacts during their own life cycle, from mining, ore processing, smelting, refining, use, recycle, or disposal $[13,17]$. A comparative life cycle assessment (LCA) of lead-containing and lead-free solders was conducted by the University of Tennessee in conjunction with the US Environmental Protection Agency (EPA) [18]. Results of that study indicate that no single alloy system has better environmental performance in all the impact categories. As shown by the normalized impact scores for the paste solders $(\mathrm{SnPb}, \mathrm{SnCu}, \mathrm{BiSnAg}$, and $\mathrm{SnAgBiCu}$; presented in Fig. 4a), the lead-free solders had demonstrably better performance in only six of the 16 impact categories, including occupational noncancer, occupational cancer, public noncancer, aquatic ecotoxicity, eutrophication, and renewable resource use compared with conventional 


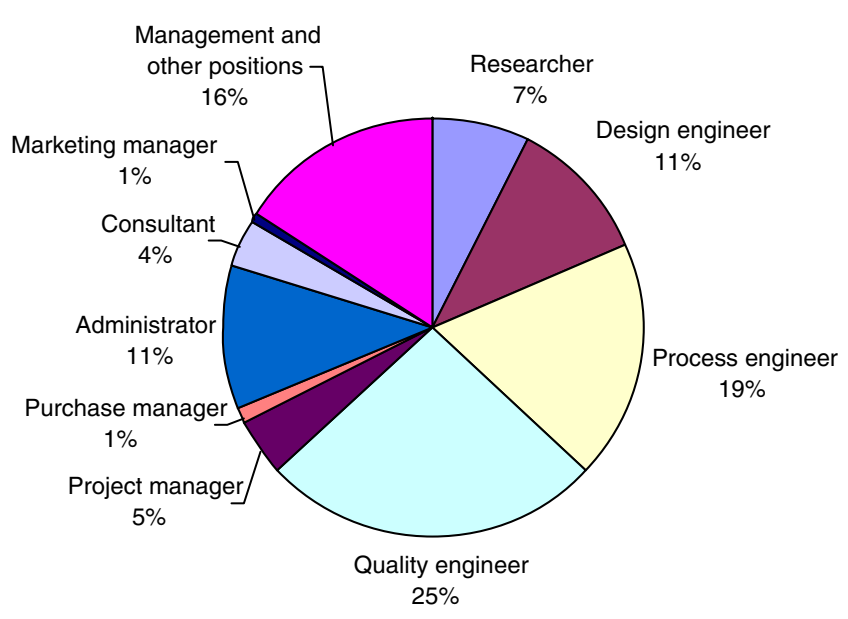

Fig. 2 Career positions of respondents

$\mathrm{SnPb}$ solder [18]. The study also demonstrated that the most promising alternative alloy system in the market - the tinsilver-copper system - cannot outperform tin-lead in most impact categories because of the significant influence of silver extraction and processing.

According to the published environmental impact studies [13-18], the primary environmental risks associated with leadcontaining solders are human health toxicity and ecotoxicity. For lead-free solders, the predominant environmental concerns are associated with resource depletion and energy consumption. We have found that the evaluation of such environmental tradeoffs varies according to different perspectives in a casespecific situation. To craft better policies for the adoption of lead-free solders in the USA, in part III of the survey, we aimed to explore individual preferences with regard to three environmental attributes: human health, resource depletion, and biodiversity (ecosystem quality). In contrast to the default Eco-Indicator $99^{\circledR}$ weighting schemes in the most popular LCA software Simapro ${ }^{\circledR}$ representing the perspective of the general public in Europe [19], the respondents to our survey represent the perspective of individuals affiliated with the US electronics industry.

The theoretical foundation of part III of the survey is conjoint rating procedure applied in the LIME model [20], which is capable of assessing individuals' preferences for each of a number of attributes through the design of profiles. The typical profile design specifies the product as composed of a combination of these attributes with different levels. In its basic form, we utilize this method to calculate weighting factors for different environmental tradeoffs by estimating the probability that a respondent will rank the set of scenarios, based on combinations of the different levels of environmental improvement presented by the lead-free transition and a monetary value representing the cost paid by individuals for each scenario.

The designed choice-based profile (Fig. 3) illustrates the scenarios representing the current environmental status quo with the comparison of other scenarios assuming that some specific environmental attributes are changed from the status quo due to the lead-free solder transition. Another variable indicates the perceived dollar value of the improved environmental performance with regard to the transition to lead-free solders. To calculate the status quo baseline value for each endpoint environmental attribute, we refer to the published EPA life cycle analysis of solders in electronics [18] and damage factor value in Eco-indicator $99^{\circledR}$ [19]. To facilitate respondents' understanding, we modify the damage indicators used in Eco-indicator $99^{\circledR}$ [19]: for the damage category of human health, "disabilityadjusted life years" is modified as "days of life expectancy lost per person per year"; for the damage category of biodiversity, "potential disappeared fraction or potentially affected fraction times area times year $\left[\mathrm{m}^{2}\right.$ year]" is modified as "extinction of species in 80 years"; for the damage category of resource depletion, "surplus energy in megajoules per kilogram extracted material" is modified as "additional energy required to obtain less available resources equivalent to years' energy consumption for a one-millionperson population in an industrial country." The three levels given in the profiles are set as a standard (equal to $100 \%$ of status quo), one half ( $50 \%$ of status quo), and close to zero (approximately $0 \%$ of status quo) damage extent of the relevant impact values.

In profile design, we set a total of 54 scenarios with the different combinations of levels and attributes and distribute them into nine versions with six scenarios for each profile. Each respondent accesses a different version randomly by clicking the website address link to the questionnaire. In part III of the survey, the respondents can choose any integer value between 1 and 10 to express the ratings of the scenarios between the least (1) and the most (10) preferred ones based on the different characteristics of the alternatives including costs, environmental implications, etc.

The analysis is based on conditional logit model and random utility theory. In the random utility theory, a definite term $V$ can be expressed by Eq. 1 . In the analysis, we applied the rank-order logistic regression model to estimate the parameter $\beta_{i}$ and $\beta_{t}$ associated with the nonmonetary attributes and the monetary attribute, respectively.

$V=\sum \beta_{i} x_{i}+\beta_{t} t$

$x_{i} \quad$ an environmental attribute vector of a profile $i$

$t$ a monetary attribute

A total differentiation of the above formula gives:

$\mathrm{d} V=\sum \frac{\partial V}{\partial x_{i}} \mathrm{~d} x_{i}+\frac{\partial V}{\partial t} \mathrm{~d} t$ 
Fig. 3 Visual-aided profile (part III of questionnaire) on environmental tradeoffs. Human health $(X): x$ days of life expectancy lost per person per year. Biodiversity $(Y)$ : extinction of $y$ species in 80 years. Resources $(Z)$ : additional energy required to obtain less available resources equivalent to $z$ year's energy consumption for a one-millionperson population in an industrial country. Extra payment $(T)$ : Annually $t$ dollars payment per person for lead-free products in excess of the normal expenditure for lead-containing products

\begin{tabular}{|c|c|c|c|c|c|}
\hline & $\begin{array}{l}\text { Human } \\
\text { Health } \\
\text { (x -days) }\end{array}$ & $\begin{array}{l}\text { Biodiversit } \\
\text { y } \\
\text { (y-species) }\end{array}$ & $\begin{array}{l}\text { Resource } \\
\text { S } \\
\text { (z-years) }\end{array}$ & $\begin{array}{l}\text { Extra } \\
\text { Payment (t- } \\
\text { dollars) }\end{array}$ & $\begin{array}{r}\text { Rating } \\
(1-10)\end{array}$ \\
\hline \multirow{2}{*}{$\begin{array}{l}\text { Scenario } 1 \\
\text { (Status Quo) }\end{array}$} & $\mathrm{x}=0.3$ & $y=6$ & $\mathrm{z}=10$ & \multirow[b]{2}{*}{$\mathrm{t}=0$} & \\
\hline & 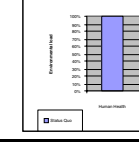 & 㥜目 & & & \\
\hline \multirow[t]{2}{*}{ Scenario 2} & $\mathrm{x}=0$ & $y=0$ & $\mathrm{z}=5$ & \multirow[b]{2}{*}{$\mathrm{t}=\$ 5.00$} & \\
\hline & \begin{tabular}{|l|} 
\\
$\square$ Status Quo \\
$\square$ Scenario 2
\end{tabular} & 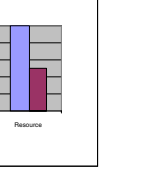 & & & \\
\hline \multirow[t]{2}{*}{ Scenario 3} & $x=0.3$ & $y=6$ & $\mathrm{z}=5$ & \multirow[b]{2}{*}{$\mathrm{t}=\$ 1.00$} & \\
\hline & \begin{tabular}{ll|}
-7 & \\
aStatus Quo \\
ascenario 3
\end{tabular} & & & & \\
\hline \multirow[t]{2}{*}{ Scenario 4} & $x=0.15$ & $y=3$ & $z=5$ & \multirow[b]{2}{*}{$\mathrm{t}=\$ 3.00$} & \\
\hline & 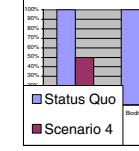 & $\bar{E}$ & & & \\
\hline \multirow[t]{2}{*}{ Scenario 5} & $\mathrm{x}=0$ & $y=6$ & $\mathrm{z}=10$ & \multirow[b]{2}{*}{$\mathrm{t}=\$ 4.00$} & \\
\hline & 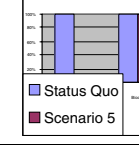 & & & & \\
\hline \multirow[t]{2}{*}{ Scenario 6} & $x=0.15$ & $y=0$ & $z=0.5$ & \multirow[b]{2}{*}{$\mathrm{t}=\$ 5.00$} & \\
\hline & 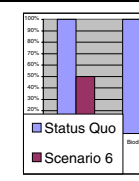 & $E$ & & & \\
\hline
\end{tabular}

Human Health $(\mathrm{X})$ : $\mathrm{x}$ days of life expectancy lost per person per year.

Biodiversity (Y): extinction of y species in 80 years.

Resources (Z): Additional energy required to obtain less available resources equivalent to z year's energy consumption for a one-million-person population in an industrial country.

Extra Payment (T): Annually t dollars payment per person for lead-free products in excess of the normal expenditure for lead-containing products.
When the utility level does not change $(\mathrm{d} V=0)$ and attributes other than the defined attribute are invariable, the marginal willingness to pay (MWTP), is derived as the negative ratio of the coefficient for each nonmonetary attribute $\left(\beta_{i}\right)$ over the coefficient for the monetary attribute $\left(\beta_{t}\right)$ as follows:

$\operatorname{MWTP}=\frac{\mathrm{d} t}{\mathrm{~d} x_{i}}=-\frac{\beta_{i}}{\beta_{t}}$

MWTP values are used in this paper to indicate the value system of the respondents of the survey. The larger MWTP value revealed, the more important the respondents regard the corresponding environmental attribute

The computed outputs for estimated coefficients of attributes from STATA ${ }^{\circledR}$ programming of rank-ordered logistic regression model are shown below:

\begin{tabular}{lllll}
\hline Rank & Coef. $\left(\beta_{i}\right)$ & Std. Err. & \multicolumn{1}{l}{$z$} & $P>|z|$ \\
\hline Health & -0.2588313 & 0.08130349 & -3.2 & 0.0007 \\
Biodiversity & -0.0179938 & 0.00436919 & -4.1 & 0.0000 \\
Resource & -0.0225319 & 0.00260681 & -8.6 & 0.0000 \\
Price & 0.0061384 & 0.00062546 & 9.8 & 0.0000 \\
\hline
\end{tabular}


Therefore, MWTP is calculated as:

$$
\begin{aligned}
\operatorname{MWTP}_{\text {Health }} & =-\frac{\beta_{\text {Health }}}{\beta_{t}}=-(-0.2588) / 0.0061 \\
& =\$ 42.20 / \text { unit damage indicator }
\end{aligned}
$$

$$
\begin{aligned}
\text { MWTP }_{\text {Biodiversity }} & =-\frac{\beta_{\text {Biodiverity }}}{\beta_{t}}=-(-0.0180) / 0.0061 \\
& =\$ 2.93 / \text { unit damage indicator }
\end{aligned}
$$

$$
\begin{aligned}
\text { MWTP }_{\text {Resource }} & =-\frac{\beta_{\text {Resource }}}{\beta_{t}}=-(-0.0225) / 0.0061 \\
& =\$ 3.67 / \text { unit damage inidicator }
\end{aligned}
$$

Thus, we elicit a weighing scheme from the estimated coefficient value of tradeoffs for avoiding a unit quantity of damage of each endpoint environmental attribute: human health, resource depletion, and biodiversity are identified as $0.86,0.08$, and 0.06 , respectively (labeled as "CJ" in Fig. 4b). This reveals the relative importance of these different environmental impacts inherent in individual preference structures associated with the lead-free transition, i.e., the priority for human health far outweighs the other two environmental attributes, resource depletion and biodiversity, between which the priority for resource depletion is slightly higher than for biodiversity.

To compare the effects of these valuation choices, we adopt three other widely used weighting schemes built into the Eco-Indicator $99^{\circledR}$ LCA methodology. These three valuation scenarios are based on cultural theory (namely, the "Egalitarian" EI99(E), "Hierarchist" EI99(H), and "Individualist" EI99(I) perspectives) and were derived from a survey of the general public in European countries $[19,21]$.

The notable differences in these four weighting schemes (Fig. 4b) highlight the distinct case-specific preferences of the respondents relative to those of the general public. We use each of the four weighting schemes $\left(W_{i} ; i\right.$, each environmental impact) to aggregate the normalized LCA impact scores $\left(S_{i} ; i\right.$, each environmental impact) for the paste solders (Fig. 4a). The results $\left(\sum_{i} S_{i} \times W_{i}\right)$ depicted in Fig. $4 \mathrm{c}$ show that the two most environmentally friendly alternatives are $\mathrm{BiSnAg}$, followed by $\mathrm{SnAgBiCu}$ regardless of the weighting scheme used. Because of the overwhelming importance of human health to our survey respondents, $\mathrm{SnPb}$ is by far the worst candidate from their perspective, whereas $\mathrm{SnAgCu}$ is the worst from the hierarchist perspective.

It may appear at first that respondents from the electronics industry will prefer $\mathrm{SnPb}$ solder because this is consistent with their technical and business concerns and the respondents are also aware that available lead-free solders have adverse environmental impacts. However, their own individual preference structures, determined without the bias of alloy composition selection, coincide well with the regulatory foundation associated with the human health effects of lead toxicity. These results offer insights into the participants' value systems, particularly when considering the potential environmental impacts of lead-free product systems and can be used to facilitate an open discussion with industrial stakeholders about environmentally initiated product transitions.

\subsection{Elicitation of Technical Tradeoff Preference Structure by a Modified Fuzzy TOPSIS Model}

Survey respondents expressed strong concerns about technical feasibility of lead-free solder in accordance with functionality. Although some test results have demonstrated that some lead-free alloys have better solder joint durability than conventional tin-lead systems in a series of thermal cycle tests, thermal shock tests, and creep tests under multiple test conditions, many substitute solders possess several reliability issues, such as intermetallic growth, creep deformation, tin whiskers, and tin pest [7-9, 22].

The implementation of lead-free solder is a significant challenge for the electronics industry and involves a complex set of technical attributes. On the basis of functionality, cost drivers, availability, manufacturability, and application-specific quality requirements of solders used in electronics, we list a set of common criteria (items "a" to " $\mathrm{m}$ " as below, with no significance to the order) that industry usually considers when selecting lead-free alternatives.

(a) Excellent solderability/wettability

(b) Relatively low cost

(c) Widest application range

(d) Process capability

(e) Abundant supply

(f) Component compatibility

(g) Melting point

(h) Thermomechanical performance

(i) Electrical performance

(j) Reliability

(k) Easy to inspect for quality

(l) Able to retrofit into current infrastructure

(m) Environmentally benign

When asked to rate the importance of these 13 relevant attributes/criteria to help guide the design and development process for lead-free solder alternatives, the respondents provided a qualitative opinion, i.e., "highly important," "medium important," or "weakly important," leading us to use a modified fuzzy TOPSIS method [23] in order to derive a quantitative rating of identified attributes/criteria for materials selection of lead-free solder alternatives. The 
Fig. 4 Valuation of life cycle impact assessment (LCIA) scores for selected paste solders. a Normalization of EPA LCIA data (Source data: [22]). (Note: The lower score indicates the lower adverse environmental effect.) b Comparison of different weighting schemes ( $C J$ : survey results from this paper; EI 99 (E, H, I): published generic weighting schemes in EcoIndicator $99^{\circledR}$ ) (Note: The higher score on the axis indicates the higher weighting factors). c Aggregation of LCIA impact scores. (Note: The lower score indicates the lower adverse environmental effect.) EI99(E): Eco-Indicator 99 (egalitarian approach); EI99(H): Eco-Indicator 99 (hierarchist approach); EI99 (I): EcoIndicator 99 (individualist approach); $C J$ : conjoint analysis approach present in this paper (Section 3.2); $\mathrm{SnPb}$ : 63Sn-37Pb; $\mathrm{SnAgCu}: 95.5 \mathrm{Sn}-4 \mathrm{Ag}-0.5 \mathrm{Cu}$;

BiSnAg: 57Bi-42Sn-1Ag;

$\mathrm{SnAgBiCu}: 92.3 \mathrm{Sn}-3.4 \mathrm{Ag}-$

$3.3 \mathrm{Bi}-1 \mathrm{Cu}$

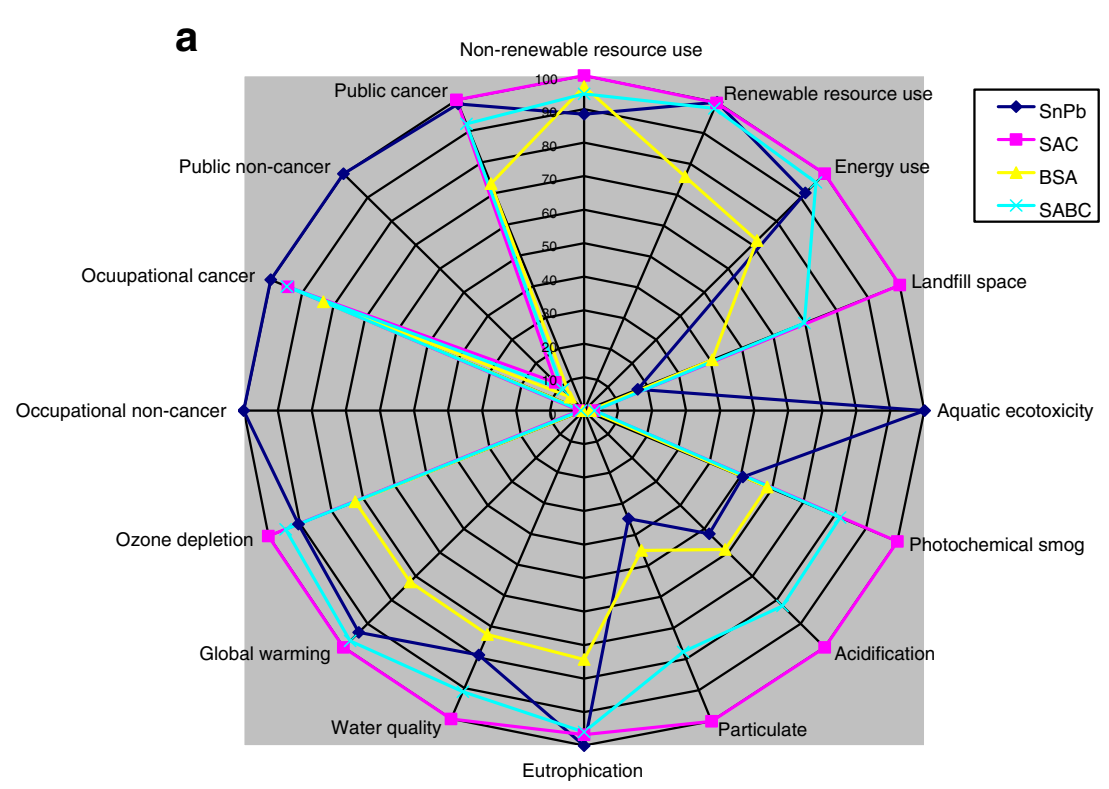

b

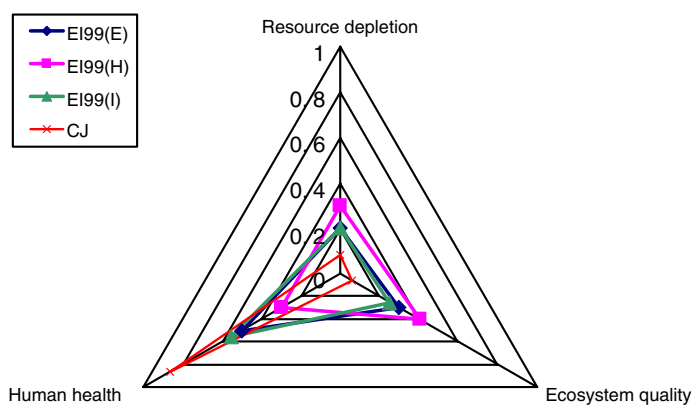

C

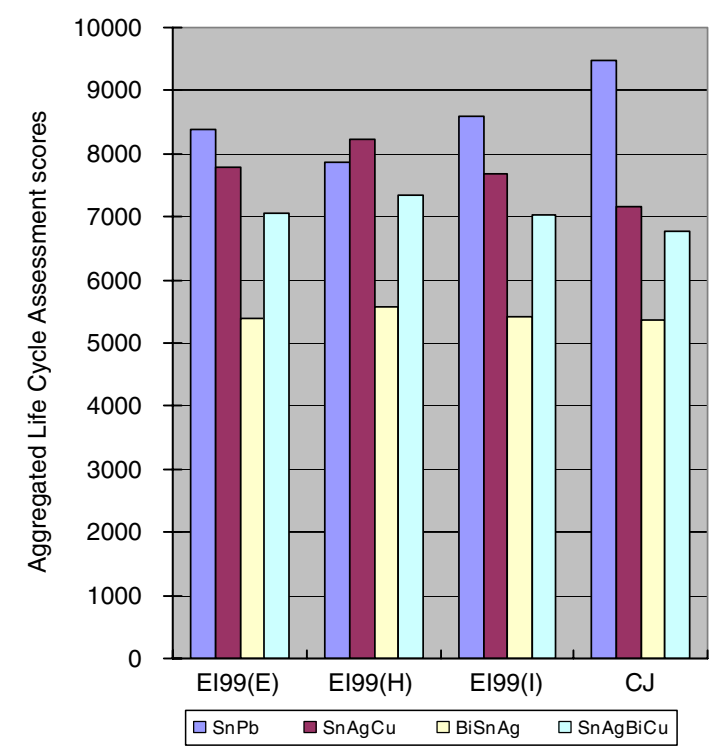

dominant criterion in a geometrical sense [23, 24], i.e., Euclidean distance. After converting the linguistic opinions into triangular numbers [25], the positive Euclidean distance $D_{j^{+}}$(separation from the most important criterion) 
and the negative Euclidean distance $D_{j-}$ (separation from the least important criterion) for each criterion are calculated using the following equations:

$D_{j+}=\sqrt{\sum\left(v_{i j}-p_{i}\right)^{2}}$

$$
D_{j-}=\sqrt{\sum\left(v_{i j}-q_{i}\right)^{2}}
$$

where $v_{i j}$ is the converted triangular fuzzy numbers;

i $1,2,3$

$j \quad 1, \ldots, n$ ( $n$ is the integer number of responses)

$p_{i} \quad(0.9,1.0,1.0)$ (the predefined triangular rating value for the most important criterion)

$q_{i}(0.1,0.1,0.2)$ (the predefined triangular rating value for the least important criterion)

Then, we use the relative closeness to the most important criterion $C_{j+}$, given by Eq. 6 , to imply the relative importance of the selected criterion that appeared in the questionnaire. A higher value of $C_{j+}$ indicates a more important criterion based on the respondents' opinion.

$C_{j+}=\frac{D_{j-}}{D_{j+}+D_{j-}}$.

The results of the fuzzy TOPSIS analysis, presented in Table 3, indicate that the three most important criteria to select an optimal lead-free solder alternative are solderability (i.e., wetting performance), reliability issues, and compatibility with the components and equipment used with conventional lead-containing solders. Besides these criteria, process capacity, other relevant technical properties, resource availability, impact of melting point to process, equipment and corresponding energy consumption, wide application range, and the inspection effects to ensure product quality and compatible infrastructure are other technical criteria to consider.

Despite many initiatives for environmental improvement, environmental impact of new alternatives was not a very important concern as weighed by the respondents from the electronics industry. Most of them do not perceive that environmental impact should be a driver when selecting appropriate alternatives. This finding is consistent with our previous discussion, where $\mathrm{SnAgCu}$ is the alternative selected by most companies even though it is not the most environmentally friendly lead-free alternative.

Although most of the alternative metals have higher extraction and processing costs, switching to lead-free solder will not significantly increase the direct production cost (i.e., materials cost) of the assembled printed wiring boards because the solder amount is small and the solder material cost represents only a very small percentage of total production cost [26]. Our survey results are consistent with this reality, as they indicate that the cost of solder materials is the least important criterion to select lead-free solders for the electronics industry. It is noted, however, that significant capital investment has been necessary for implementation of the lead-free transition because of the need for process, component, and equipment redesign, as well as consideration of changes in mass production yield, reliability and rework performance, and documentation requirements [26]. For recyclers, a high cost for the alternative materials may become an incentive to promote more recycling activities for end-of-life lead-free electronic products.

\subsection{Analysis of Corporate Lead-Free Adoption Strategy by an Explanatory Model}

If the supply chain infrastructure embraces the lead-free transition, the impact on the overall industry strategy could
Table 3 Converted quantitative importance ratings of criteria for lead-free solder selection

\begin{tabular}{lcc}
\hline Criteria for choosing lead-free solder & Converted rating & Rank based on the importance \\
\hline Solderability & 0.66 & 1 \\
Reliability & 0.65 & 2 \\
Component compatibility & 0.64 & 3 \\
Process capacity & 0.62 & 4 \\
Electrical characteristics & 0.60 & 5 \\
Thermomechanical characteristics & 0.59 & 6 \\
Abundant resource supply & 0.57 & 7 \\
Melting point & 0.55 & 8 \\
Application range & 0.54 & 9 \\
Convenience of inspection & 0.54 & 10 \\
Infrastructure & 0.52 & 11 \\
Environmental performance & 0.51 & 12 \\
Low materials cost & 0.48 & 13 \\
\hline
\end{tabular}


be significant. Those companies that are unprepared, or underprepared, are presented with a higher risk if the supply chain starts to switch to a lead-free infrastructure. It is estimated that the US industry could lose approximately \$240 billion over a 3-year period if the USA does not respond to lead-free initiatives quickly and competitively [27]. Such transition also demands significant resource investment and capital expenditures. Accordingly, survey respondents expressed concerns with regard to business risks.

One purpose of the survey is to study the factors, such as business type, membership of industrial association, geographic areas of business activity, and company scale, that influence company decision making on the lead-free transition. From this perspective, we applied a binary logit regression model to predict corporate lead-free adoption strategy using current involvement in lead-free activities as our binary dependent variable $Y(y=1$ : active involvement; $y=0$ : no involvement). We used a series of explanatory variables $X$ to characterize the company's profile: organization membership, company scale, business type, and spatial coverage, etc. The goal was to detect the influence of these variables on the dependent variable - the current corporate adoption of lead-free solders. In the first step, we checked and removed some excessively correlated variables by a series of general statistical procedures. Then, we ran a binary logit regression model to select the appropriate variables to include in the explanatory model. For a binary response variable $Y$, the logit regression has the form given in Eq. 7 :

$\operatorname{Logit}(p)=\log _{e}[p /(1-p)]=\beta^{\prime} x$

Where $p$ is $\operatorname{Prob}(Y=y 1)$ for $y 1$ as one of two ordered levels of $Y, \beta$ is the parameter vector, and $x$ is the vector of explanatory variables. By estimates of the parameter vector (i.e., the corresponding coefficients), we examined the significance of factors that may influence corporate decision making about the lead-free transition.
Table 4 shows the output obtained by the binary logit regression to determine the significant factors affecting the corporate involvement with the adoption of lead-free products. It is worth noting that the companies involved in the lead-free transition have some common characteristics, which we define as those significant variables with a $p$ value shown in Table 4 less than a threshold value of 0.05: "EMS companies," "OEM companies," "international market," and "other industrial organizations [mostly identified as Surface Mount Technology Association (SMTA)]." To analyze the impact of these binary dependent variables, we calculate discrete changes in the predicted probability of the lead-free adoption by changing one binary variable at a time and keeping all other variables at their baseline value. Our baseline is a domestic company neither belonging to EMS or OEM business type. The results are also presented in Table 4.

Our first finding is that the company's business type is important in determining the strategy of lead-free adoption. Compared to the baseline, the probability of lead-free adoption increases by $65 \%$ when it is an EMS company and by $24 \%$ when it is an OEM company. OEMs take full responsibility and risk for the successful transition to leadfree products in accordance with the RoHS Directive. If they fail to do so, the noncompliance penalty will either be loss of competitive position or large fines. Consequently, OEMs require their suppliers and manufacturing contractors, EMS companies, to confirm their "Certificates of Compliance" as qualified suppliers [28]. Thus, it is not surprising that these main executors of the RoHS Directive, the OEM and EMS companies, will take active attitudes towards successful lead-free product development and service transitions. Furthermore, the EMS companies are more progressive than the OEMs in lead-free solder adoption. This could be due to a lack of regulatory and legislative pressure within the USA. Under a very competitive business environment and decreasing profitability,

Table 4 Significant explanatory variables for current corporate adoption of lead-free products

Binary logit regression model (Software: Minitab ${ }^{\circledR} 12.0$ )

\begin{tabular}{|c|c|c|c|c|c|}
\hline \multirow{2}{*}{$\begin{array}{l}\text { Dependent variable } \\
\text { Explanatory variables }\end{array}$} & \multicolumn{3}{|c|}{$1=$ adoption; $0=$ no adoption } & \multirow{2}{*}{$\begin{array}{l}\text { Variables } \\
\text { Baseline probabilities }\end{array}$} & \multirow{2}{*}{$\begin{array}{l}\text { Predicted } \\
\text { probabilities } \\
0.196\end{array}$} \\
\hline & $\begin{array}{l}\text { Coefficient } \\
\text { estimate }\end{array}$ & $\begin{array}{l}\text { Standard } \\
\text { error }\end{array}$ & $p$ value & & \\
\hline "International market" (yes = 1) & 1.226 & 0.647 & 0.058 & "International market" (baseline indicator no $\rightarrow$ yes) & +0.258 \\
\hline "EMS" (yes = 1) & 3.124 & 0.869 & 0.000 & "EMS" (baseline indicator no $\rightarrow$ yes) & +0.651 \\
\hline “OEM" (yes = 1) & 1.146 & 0.529 & 0.030 & "OEM" = 1 (baseline indicator no $\rightarrow$ yes) & +0.238 \\
\hline "SMTA" (yes = 1) & 1.765 & 0.738 & 0.017 & "SMTA" = 1 (baseline indicator no $\rightarrow$ yes) & +0.391 \\
\hline
\end{tabular}

$E M S$ electronic manufacturing service, OEM original equipment manufacturer, SMTA Surface Mount Technology Association 
many small- and medium-size EMS companies export their service to the international market. Therefore, these EMS companies, which are staying ahead of US lead-free regulations, can minimize future risks and liabilities. Furthermore, they can have a competitive edge over those struggling to keep up in the future.

In the industrial context, to strengthen the competitiveness on the worldwide market, our survey results show that active members of professional trade organizations or industrial associations, such as SMTA, American Electronics Association, Government Electronics and Information Technology, International Tin Research Institute, and Industry Council for Electronic Equipment Recycling, attempt to promote compliance with the RoHS Directive in terms of their easy access to extensive professional resources and guides for regulatory compliance. Particularly, when a company is an active member of SMTA, the probability of lead-free adoption is increased by $39 \%$ compared with the baseline.

Because of direct regulatory pressure, the companies targeting European and Asian markets are more likely to be implementing lead-free transitions than those with mainly domestic markets. This statement is consistent with the result in Table 4 that the probability of lead-free adoption increases by $26 \%$ compared with the baseline when the company is targeting an international market.

Another finding in this survey is that the effect of company scale is not a significant factor influencing corporate decision making on lead-free adoption. A priori, we hypothesized that larger companies would be more active than smaller ones in adopting environmental activities because they have access to more capital. Our results suggest, however, that small and medium enterprises in the US electronics industry are indeed knowledgeable about the potential impact of the ongoing lead-free legislation and they are actively engaged in the adoption of lead-free products.

\section{Conclusions and Recommendations}

Recent global and regional restricted substance regulations and policies have driven the US electronics industry to prepare for and implement the switch to lead-free products and service systems. Our research has revealed important concerns within the US electronics industry about the scientific evidence and effectiveness of phasing out lead in solder for electronic products in terms of technical and economic feasibility. Although significant lead-free transition has occurred in the US since the survey was conducted, there is still no US policy for lead-free electronics (all motivation is derived from European law) [29]. Furthermore, the case of lead-free electronics serves as a model study for current and future initiatives (such as the State of California's Green Chemistry Initiative and the US EPA's Essential Principles for Reform of Chemicals Management Legislation $[30,31])$ to eliminate the use of other toxic substances in products. Thus, we provide our concluding remarks in the context of safer alternatives in general, although described specifically for lead in electronics.

Designing US legislation to phase out lead from electronics (or other toxic substances from other complex products) will not be an easy task. It should take into account not only the known health risks associated with lead (the precautionary principle), but also a scientifically documented assessment of alternative systems for which all three sustainability characteristics (human health, biodiversity, and resource depletion) are considered throughout the life cycle of the product system. This type of approach is currently under consideration as the State of California develops its Safer Alternatives regulations [32]. The environmental and the social benefits of legislation need to be the subject of rigorous analysis and an informational campaign to disseminate knowledge and stimulate industrial actions. Technical feasibility, particularly with respect to product quality and reliability, must not be sacrificed with the adoption of alternatives. Both industry and government agencies should participate in resolving key technical barriers and addressing them in future design efforts and regulatory reviews. To facilitate the sharing of technical information and industrial experience in a timely fashion, a decision support information system should be promoted. Furthermore, from a business perspective, the phase out of lead needs to be envisioned not simply as a compliance or market share issue, but as an opportunity for corporate decision makers to move in a strategically beneficial direction, with minimal economic risk. The combined consideration of these three facets, environmental improvement, technical enhancement, and successful business strategy, is essential in designing legislative initiatives that will successfully result in the phase out of lead in electronic product systems. This paper illustrates an interdisciplinary approach that provides a means to consider the three facets concurrently and in detail, while incorporating the value system of the relevant stakeholders, in this case, industry personnel, which is a critical element in the interpretation of the results.

Acknowledgements The successful survey process relies on the input of all 109 survey respondents from IPC and people participating in the pilot presurvey test. So, especially, we acknowledge these individuals that volunteered their time and effort to respond to our survey questionnaire. We thank Dr. Jean-Daniel Saphores from UC Irvine for the discussions and suggestions in the analysis and interpretation of survey results. We also thank Chris Derr at UC Davis for his many contributions to the programming of the webbased questionnaire and the data collection process. This paper is based upon work supported by the National Science Foundation under grant number CMS-0524903. 
Open Access This article is distributed under the terms of the Creative Commons Attribution Noncommercial License which permits any noncommercial use, distribution, and reproduction in any medium, provided the original author(s) and source are credited.

\section{References}

1. CEC (Commission of the European Communities). (2001). Amended proposal for a Directive of the European Parliament and of the council on the restriction on the use of certain hazardous substances in electrical and electronic equipment. Official Journal of the European Communities, C240E, 298-302.

2. EU (the European Parliament and the Council of the European Union). (2003). Directive 2002/95/EC of the European Parliament and of the Council on the restriction of the use of certain hazardous substances in electrical and electronic equipment. Official Journal of the European Union, 37, 19-23.

3. EU (the European Parliament and the Council of the European Union). (2003). Directive 2002/96/EC of the European Parliament and of the Council of 27 January 2003 on waste electrical and electronic equipment (WEEE). Official Journal of the European Union, 37, 24-39.

4. Kang, H., \& Schoenung, J. M. (2005). Electronic waste recycling: A review of U. S. infrastructure and technology options. Resources Conservation and Recycling, 45(4), 368-400.

5. Ciocci, R., \& Pecht, M. (2006). Impact of environmental regulations on green electronics manufacture. Microelectronics International, 23(2), 45-50.

6. Lincoln, J. D., Ogunseitan, O. A., Shapiro, A. A., \& Saphores, J.-D. M. (2007). Leaching assessments of hazardous materials in cellular telephones. Environmental Science \& Technology, 41, 2572-2578.

7. Ganesan, S., Xie, J.-S., Qi, H., \& Osterman, M. (2006). Review of lead-free solder joint reliability. In S. Ganesan \& M. Pecht (Eds.), Lead-free electronics (Ch. 5). Hoboken: Wiley.

8. Hwang, J. S. (2005). Implementing lead-free electronics: A manufacturing guide. New York: McGraw-Hill.

9. Puttlitz, K. J., \& Stalter, K. A. (Eds.). (2004). Handbook of leadfree solder technology for microelectronic assemblies. New York: Marcel Dekker.

10. Griffiths, P., Brennan, R., \& Wayman, M. (2003). Priority waste stream project: waste electrical and electronic equipment. Report PR/CXS/02/2003 for the Scottish Environment Protection Agency.

11. Vojak, B. A., Suarez, C. A., Peters, L., \& Sundararajan, M. (2005). Sources of information used in technology planning within the nanotechnology industry. 2005 International Symposium on Electronics and the Environment Proceedings, pp 53-57.

12. Ciocci, R., Pecht, M., \& Ganesan, S. (2006). Lead-free electronics: Overview. In S. Ganesan \& M. Pecht (Eds.), Lead-free electronics (Ch. 1). Hoboken: Wiley.

13. Griese, H., Muller, J., Reichl, H., Somi, G., Stevels, A. B., \& Zuber, K. H. (2000). Environmental assessment of lead free interconnection systems. Presented at 2000 Proc. Symp. on Lead Free Interconnect Technology. Boston: SMTA.

14. Townsend, T. G. (2002). Evaluation of leaching test results of lead-free solders. A Report for Abt Associates, Inc.

15. Jang, Y.-C., \& Townsend, T. G. (2003). Leaching of lead from computer printed wire boards and cathode ray tubes by municipal solid waste landfill leachates. Environmental Science and Technology, 37(20), 4778-4784.
16. Li, Y., Richardson, J. B., Walker, A. K., \& Yuan, P.-C. (2006). TCLP heavy metal leaching of personal computer components. Journal of Environmental Engineering, 132, 497-504.

17. Ku, A. Y. (2002). Evaluation of the feasibility of lead-free solders. Master thesis. University of California, Irvine, 2002.

18. Geibig, J. R., \& Socolof, M. L. (2005). Solders in electronics: A life cycle assessment. EPA 744-R-05-001, US Environmental Protection Agency.

19. Goedkoop, M., \& Spriensma, R. (2001). The Eco-indicator 99: A damage oriented method for life cycle impact assessment. PRé Inc.

20. Itsubo, N., Sakagami, M., Washida, T., Kokudu, K., \& Inaba, A. (2004). Weighting across safeguard subjects for LCIA through the application of conjoint analysis. International Journal of Life Cycle Assessment, 9(3), 196-205.

21. Hofstetter, P., Baumgartner, T., \& Scholz, R. W. (2000). Modeling the value sphere and the ecosphere: Integrating the decision makers' perspectives into LCA. International Journal of Life Cycle Assessment, 5(3), 161-175.

22. Shapiro, A. A., Bonner, J. K., Ogunseitan, O. A., Saphores, J.-D. M., \& Schoenung, J. M. (2006). Implications of $\mathrm{Pb}$-free microelectronics assembly in aerospace applications. IEEE Transactions, Components and Packaging Manufacturing Technology, 29, 60-70.

23. Pochampally, K. K., \& Gupta, S. M. (2004). Efficient design and effective marketing of a reverse supply chain: A fuzzy logic approach. International Symposium of Environment and Electronics Proceeding, 2004, 321-326.

24. Filar, J. A., Ross, N. P., \& Wu, M.-L. (2003). Environmental assessment based on multiple indicators. 2003 Calcutta Statistical Association Bulletin, 54, 93-104.

25. Klir, G. J., \& Yuan, B. (1995). Fuzzy sets and fuzzy logic: Theory and applications. Upper Saddle River: Prentice Hall PTR.

26. Shimohashi, K., Zhou, X., \& Schoenung, J. M. (2009). A testrework process yield performance model for estimation of printed wiring board assembly cost. International Journal of Production Economics, 119(1), 161-173.

27. EPA (US Environmental Protection Agency) (2005). Solders in electronics: A life-cycle assessment-A fact sheet, August 2005. http://www.epa.gov/dfe/pubs/solder/lead-free-fact1.pdf. Accessed 14 April 2006.

28. Dastmalchi, B., \& Vermeij, R. (2005). Transition to RoHS: The seven common pitfalls to avoid. A white paper authorized by Symphony Consulting, Inc. and Arena Solutions, 2005. http://www.ies.ncsu.edu/documentation/productdocumentation/ Transition-to-RoHS.pdf. Accessed 20 July 2006.

29. Ogunseitan, O. A., Schoenung, J. M., Saphores, J.-D. M., \& Shapiro, A. A. (2009). The electronics revolution: From Ewonderland to E-wasteland. Science, 326, 670-671.

30. California Department of Toxic Substances Control. (2007). Green chemistry. http:/www.dtsc.ca.gov/PollutionPrevention/ GreenChemistryInitiative/index.cfm. Accessed 3 May 2010.

31. EPA (US Environmental Protection Agency) (2010). Essential principles for reform of chemicals management legislation. http:// www.epa.gov/oppt/existingchemicals/pubs/principles.html. Accessed 3 May 2010.

32. California Department of Toxic Substances Control. (2010). California's green chemistry initiative: Accelerating the quest for safer products-DTSC releases outline of draft regulations. http://www.dtsc.ca.gov/PollutionPrevention/GreenChemistry Initiative/safer_products_regs_outline.cfm. Accessed 3 May 2010 . 